\title{
INFLUÊNCIA DAS ESPÉCIES EXÓTICAS INVASORAS NA EXPRESSÃO DA DIVERSIDADE DA ARBORIZAÇÃO DE RUAS DE CURITIBA-PR
}

\author{
THE INFLUENCE OF INVASIVE ALIEN SPECIES ON DIVERSITY EXPRESSION \\ OF STREET TREES OF CURITIBA-PR
}

\author{
Rogério Bobrowski ${ }^{1}$, Daniela Biondi ${ }^{2}$
}

\begin{abstract}
RESUMO
A diversificação da composição de espécies é objetivo primordial do planejamento da arborização de ruas. Sem conhecimento técnico especializado e reconhecimento do comportamento ecológico de uma espécie pode-se introduzir aquelas com potencial invasor. Este trabalho objetivou analisar a composição da diversidade de espécies na arborização de ruas, a contribuição das espécies exóticas e exóticas invasoras na expressão do índice de Shannon-Wiener e a variação da diversidade de espécies entre duas ocasiões de medição. Para isso foram remedidas 15 unidades amostrais de um inventário de 1984, sendo analisada a proporção de espécies nas parcelas e entre os inventários. Constatou-se que para as espécies exóticas invasoras mais freqüentes, em ambos os inventários (Ligustrum lucidum e Melia azedarach), houve redução na quantidade de indivíduos. Entretanto, para Eriobotrya japonica, Hovenia dulcis e Pittosporum undulatum as proporções de aumento foram respectivamente iguais a $70 \%, 1100 \%$ e $700 \%$. Os valores do índice se Shannon-Wiener foram significativamente diferentes $(p<0,01)$ para 12 parcelas e para o total amostrado. A remoção das espécies exóticas invasoras não alterou significativamente $(p>0,01) \circ$ valor do índice para o ano de 2010 , mas com a remoção das espécies exóticas as alterações se tornaram significativas $(p<0,01)$ acarretando em menores valores do índice.
\end{abstract}

Palavras-chave: Ecologia urbana; Silvicultura urbana; Manejo da arborização de ruas.

\section{ABSTRACT}

The diversification of species composition is the primary objective of urban forestry planning. Without specialized technical knowledge and recognition of the ecological performance of a species it can be introduced those with invading potential. This study intended to analyze species diversity of streets trees, the contribution of exotic species and invasive ones to the expression of Shannon-Wiener index and the variation of species diversity between two occasions of measurement. For this purpose, it was remeasured 15 unit plots of an inventory of 1984, being examined the proportion of species on the plots and between inventories. It was noted that for invasive alien species more frequently in both inventories (Ligustrum lucidum and Melia azedarach), there was a reduction in the number of individuals. However, for Eriobotrya japonica, Hovenia dulcis and Pittosporum undulatum the increase of proportions were respectively equal to $70 \%, 1100 \%$ and $700 \%$. The values of the Shannon-Wiener index were significantly different $(p<0.01)$ for 12 unit plots and for the total data sampled. The removal of invasive alien species has not changed significantly $(p>0.01)$ the value of the index for the year 2010 , but with the removal of alien species changes have become significant $(p<0.01)$ causing lower index values.

Keywords: Urban ecology; Urban forestry; Street tree management.

Recebido em 03.08.2015 e aceito em 21.09.2015

1 Engenheiro Florestal, Dr., Professor Adjunto do Departamento de Engenharia Florestal da Universidade Estadual do CentroOeste. Irati/PR. E-mail: rogerio@irati.unicentro.br

2 Engenheira Florestal, Dra., Professora Titular do Departamento de Ciências Florestais da Universidade Federal do Paraná. Curitiba/PR. E-mail: dbiondi@ufpr.br 


\section{INTRODUÇÃO}

A chave para a sustentabilidade da arborização de ruas reside não apenas na seleção de espécies com características peculiares desejáveis (tamanho, floração, textura da folhagem, resistência, dentre outras), mas também na promoção de maior diversidade arbórea dentro dessas populações (GALVIN, 1999), visto que isso é um dos principais objetivos do processo de gestão deste componente arbóreo (KENNEY; VAN WASSENAER; SATEL, 2011; BOBROWSKI; BIONDI, 2012).

Para Kenney, Van Wassenaer e Satel (2011), a diversidade de espécies compondo a arborização de uma cidade pode ser utilizada como um atributo para mensurar a sustentabilidade da mesma, pois pode ser considerada tanto para a manutenção da diversidade de espécies quanto da diversidade genética que determinam a estabilidade, a resistência e a resiliência diante de situações desfavoráveis (GALVIN, 1999; RAUPP; CUMMING; RAUPP, 2006; TEIXEIRA; SILVA; TATSCH, 2011). De acordo com Sreetheran, Adnan e Khairil Azuar (2011), o exame da diversidade ocorrente na arborização de ruas permite, de forma mais eficiente, o planejamento e a gestão de estratégias de plantio.

Devido ao predomínio de baixa diversidade de espécies compondo a arborização das cidades brasileiras, o ataque de pragas e doenças pode ter maior probabilidade de ocorrência (SILVA FILHO; BORTOLETO, 2005). Por outro lado, a maior diversificação visa, principalmente, a redução das perdas ocasionadas por pragas, doenças, e outros fatores adversos, além do prolongamento dos benefícios proporcionados pelas árvores nas ruas (GALVIN, 1999). Para isso, há necessidade de compatibilizar a diversificação de espécies com a uniformização de composição, para também promover efeitos estéticos com os diferentes atributos das espécies arbóreas (BOBROWSKI; BIONDI, 2012).

Atualmente há muita preocupação com a biodiversidade nas áreas urbanas e isto se reflete na diversificação do número de espécies produzidas em viveiro. Entretanto, esta preocupação com a diversificação de espécies é problemática, pois muitas vezes não há tempo suficiente para realizar pesquisas sobre as espécies introduzidas. Desta forma, ocorre a produção e a utilização de espécies indesejáveis para o ambiente e para o homem, tais como as plantas tóxicas e exóticas invasoras (BIONDI; LEAL, 2008).

A sociedade humana tem alterado as condições naturais dos ecossistemas e de seus recursos, sempre em favor de propósitos diversos (exploração florestal, extração de minerais, construção de cidades, entre outros). Isto tem causado impactos como a introdução de espécies exóticas que diante de condições favoráveis podem assumir caráter invasor e constituir um dos mais expressivos impactos biológicos negativos (MOONEY, 2005). As espécies declaradas exóticas invasoras são aquelas de ocorrência não natural em 
um ecossistema considerado e que adquirem vantagem competitiva devido ao desaparecimento de obstáculos à sua proliferação (BIONDI; PEDROSA-MACEDO, 2008).

A existência de espécies exóticas invasoras compondo a arborização de ruas serve como fonte dispersora de propágulos, os quais, ao serem levados ao componente áreas verdes da floresta urbana, podem desencadear o processo de contaminação biológica (BOBROWSKI, 2011). Da mesma forma, o cultivo de plantas exóticas para ornamentação de jardins e praças é uma das principais rotas de introdução de espécies potencialmente invasoras, podendo responder por mais da metade dos casos de invasão biológica (BIONDI; PEDROSA-MACEDO, 2008; MORO; WESTERKAMP, 2011).

Diante do exposto, objetivou-se analisar a composição da diversidade de espécies na arborização de ruas, a contribuição das espécies exóticas e exóticas invasoras na expressão do índice de Shannon-Wiener e a variação da diversidade de espécies entre duas ocasiões de medição de um inventário da arborização de ruas.

\section{MATERIAL E MÉTODOS}

A coleta de dados foi realizada no ano de 2010 em 15 unidades amostrais de um inventário realizado em 1984 na arborização de ruas de Curitiba, capital do Estado do Paraná, a qual está localizada na porção leste do Estado, no primeiro planalto paranaense entre as coordenadas $25^{\circ} 25^{\prime} 48^{\prime \prime} S$ e $49^{\circ} 16^{\prime} 15^{\prime \prime} \mathrm{W}$. Os ecossistemas que recobrem a região de Curitiba são a Floresta Ombrófila Mista e a Estepe Gramíneo-Lenhosa, sendo ambos integrantes do Bioma da Mata Atlântica (BIONDI; LEAL, 2008; BIONDI; PEDROSAMACEDO, 2008).

O trabalho consistiu na remedição de variáveis quali-quantitativas (DAP, altura total, diâmetro de copa, distância entre árvores, condição geral da árvore, dentre outros) das árvores encontradas dentro dos limites de quinze unidades amostrais de um inventário realizado em 1984 e em 2010.

O método de amostragem utilizado foi o de área fixa, com parcelas de $500 \times 500 \mathrm{~m}$, e o processo de amostragem adotado foi o aleatório irrestrito. Estes procedimentos foram definidos na primeira ocasião de medição e serviram de base para a segunda ocasião de medição em 2010, a fim de efetuar a análise comparativa dos dados. Neste trabalho não foi efetuada nova análise da intensidade amostral e consequente adequação do número de amostras para representar a população da arborização de ruas da cidade.

A partir da florística amostral foi realizada a análise da composição por espécies exóticas e exóticas invasoras, para o total amostrado em cada ano de avaliação. A caracterização das espécies exóticas invasoras presentes na arborização de ruas de 
Curitiba foi feita de acordo com as disposições do Decreto Municipal 473/2008 e Portaria do Instituto Ambiental do Paraná 125/2009 (apenas espécies da categoria I, ou seja, aquelas que não devem ser cultivadas). As espécies consideradas exóticas invasoras por estes instrumentos legais, para os ecossistemas originais onde está inserida a cidade de Curitiba, são: Eucalyptus spp, Eriobotrya japonica, Hovenia dulcis, Ligustrum lucidum, Morus nigra, Pinus spp, Pittosporum undulatum e Melia azedarach. A caracterização da origem das espécies amostradas foi feita de acordo com a metodologia adotada por Biondi e Leal (2008), as quais propuseram o enquadramento das espécies em três classes: Exóticas no Brasil, Nativas do Brasil e Nativas de Curitiba.

Para avaliação da alteração da diversificação de espécies foi utilizado o índice de Shannon-Wiener, o qual mede o grau de incerteza em se predizer a que espécie pertence um indivíduo selecionado aleatoriamente na população amostrada (MAGURRAN, 2011). Foram analisadas as diferenças entre a diversidade total, diversidade sem espécies exóticas invasoras e diversidade sem espécies exóticas, pelo "Teste t" de Hutcheson (MAGURRAN, 2011). De acordo com Silva Filho e Bortoleto (2005), o índice de Shannon-Wiener está entre os mais utilizados como ferramenta de manejo e apoio aos planos diretores da arborização urbana.

\section{RESUTADOS E DISCUSSÃO}

Na Tabela 1 estão relacionadas as espécies exóticas invasoras e a quantidade de árvores amostradas na primeira ocasião de medição do inventário, em 1984, e na segunda ocasião, em 2010.

Tabela 1.Quantidade $(\mathrm{N})$ e proporção $(\mathrm{P})$ de cada espécie exótica invasora observada em ambos os inventários da arborização de ruas de Curitiba, respectivamente para os anos 1984 e 2010

Table 1. Quantity $(\mathrm{N})$ and proportion $(\mathrm{P})$ of each invasive alien species observed for both inventories of Curitiba street trees, respectively to the years of 1984 and 2010

\begin{tabular}{lcccc} 
Espécie & \multicolumn{2}{c}{ Ano } & $\mathbf{1 9 8 4}$ & \multicolumn{2}{c}{ Ano 2010 } \\
Eriobotrya japonica (Thunb.) Lindl. & $\mathbf{N}$ & $\mathbf{P}$ & $\mathbf{N}$ & $\mathbf{P}$ \\
Eucalyptus viminalis Labill. & 10 & 0,23 & 17 & 0,39 \\
Eucalytus cinerea F. Muell. ex Benth. & 2 & 0,05 & 1 & 0,02 \\
Eucalytus saligna Sm. & 4 & 0,09 & 0 & 0 \\
Hovenia dulcis Thunb. & 0 & 0 & 3 & 0,07 \\
Ligustrum lucidum W.T. Aiton & 1 & 0,02 & 11 & 0,25 \\
Melia azedarach L. & 644 & 14,81 & 531 & 12,18 \\
Morus nigra L. & 108 & 2,48 & 87 & 2 \\
Pinus elliottii Engelm. & 0 & 0 & 15 & 0,34 \\
Pinus taeda L. & 5 & 0,12 & 0 & 0 \\
Pittosporum undulatum Vent. & 5 & 0,12 & 4 & 0,09 \\
Total & 2 & 0,05 & 14 & 0,32 \\
\hline
\end{tabular}


A quantidade de espécies exóticas invasoras manteve-se exatamente a mesma entre 1984 e 2010, sendo observada mudança apenas na composição destas. As mudanças observadas entre a listagem de 1984 e 2010 referem-se à saída de Eucalyptus viminalis e Pinus elliottii da lista de 1984, com a entrada de Morus nigra e Eucalyptus saligna, todas provenientes de plantios voluntários, ou seja, aqueles feitos sem atender ao padrão de composição florística da arborização de ruas adotado pela prefeitura municipal (BOBROWSKI; BIONDI, 2012).

Para a quantidade total de indivíduos desta categoria de espécies houve redução de $12,55 \%$ no período de 26 anos entre avaliações. Para Ligustrum lucidum e Melia azedarach que apresentaram as maiores proporções de indivíduos em ambos os inventários, as proporções de redução foram respectivamente iguais a 17,55\% e 19,44\%. Por outro lado, as espécies Eriobotrya japonica, Hovenia dulcis e Pittosporum undulatum apresentaram as maiores proporções de aumento, respectivamente iguais a $70 \%, 1100 \%$ e $700 \%$.

Das espécies descritas na Tabela 1, Ligustrum lucidum e Melia azedarach representam a quantidade mais expressiva de árvores, pois apenas essas duas espécies faziam parte de plantios planejados e executados pela Prefeitura de Curitiba (BOBROWSKI, 2011). Para as demais espécies a quantidade variável está associada principalmente aos plantios irregulares (aqueles feitos voluntariamente pela população), mas também, à condução de regeneração espontânea em canteiros da arborização de ruas. Estas constatações associam-se às afirmações de Biondi e Pedrosa-Macedo (2008) de que a maioria das espécies invasoras presentes nas cidades é introduzida pela população ou pelo órgão público. Os autores complementaram esta informação afirmando que em Curitiba, principalmente, a população tem uma grande parcela de responsabilidade pela introdução de espécies exóticas invasoras, devido a aspectos culturais.

Para Eriobotrya japonica, Hovenia dulcis e Pittosporum undulatum, que apresentaram aumento expressivo entre as duas ocasiões de avaliação, são comuns relatos de invasão biológica em fragmentos da Floresta Ombrófila Mista e como oportunistas no processo inicial de regeneração natural (ROSA; LONGHI, LUDWIG, 2008).

Emer e Fonseca (2010) e Silva et al. (2011) concluíram que é baixo o potencial invasor de espécies do gênero Eucalyptus e Pinus, respectivamente em áreas próximas aos talhões de plantios comerciais e no interior de remanescentes da Floresta Ombrófila Mista não perturbados. Entretanto, para o gênero Pinus o potencial invasor se dá em regiões de Campos (Estepe gramíneo-lenhosa) ou com formação florestal mais esparsa como o Cerrado ou em áreas desprovidas de vegetação devido a ações antrópicas diversas (FALLEIROS; ZENNI; ZILLER, 2011). 
A remoção e substituição dessas espécies deve ser adotada como uma medida urgente de manejo, porém de forma ordenada, a fim de diminuir e evitar a dispersão de sementes da arborização de ruas para os maciços florestais nativos da cidade e região metropolitana, para as áreas livres de cobertura arbórea adjacentes às ruas e para as demais categorias de áreas verdes (praças e parques) que podem ter sua qualidade e integridade biológica depreciada. Entretanto, o planejamento da remoção ordenada ou substituição gradativa deve ser realizada de forma a evitar perdas repentinas ou drásticas da arborização existente, pois por mais que as árvores sejam de espécies exóticas invasoras elas auxiliam na oferta de alguns benefícios ambientais como a regulação microclimática, devido ao sombreamento proporcionado às ruas. Segundo Blum, Borgo e Sampaio (2008), as espécies exóticas invasoras têm causado a perda de biodiversidade em diversos ecossistemas terrestres, afetando a economia e a saúde humana.

Biondi e Pedrosa-Macedo (2008) recomendaram ações dos órgãos municipais de Curitiba, a fim de promover a educação da população, e a adoção de práticas de manejo nas áreas verdes (praças e parques) e arborização de ruas, sempre fomentadas com informações técnico-científicas atuais, bom senso e respeito para com a vegetação de ocorrência natural da cidade, evitando impactos sobre ambientes limítrofes.

Tal como constatado neste trabalho, é comum a utilização de espécies exóticas na arborização de ruas das cidades brasileiras, as quais passam a representar um alto percentual na composição de espécies. Trabalhos como os de Calixto Junior, Santana e Lira Filho (2009), Pires et al. (2010), Strangheti e Silva (2010) e Moro e Westerkamp (2011) também relataram proporções expressivas dessa categoria de espécies. Segundo Biondi, Leal e Cobalchini (2007), a constatação usual de espécies exóticas na arborização urbana se deve à falta de conhecimento para utilização de espécies nativas, principalmente com relação ao comportamento das espécies no meio urbano e às características de produção das mudas.

A caracterização e a comparação da origem das espécies amostradas, entre ambos os inventários, estão apresentadas na Tabela 2. O resultado obtido demonstra que apesar do aumento no número de espécies para cada tipo de origem as proporções mantiveram-se aproximadas, mesmo havendo apenas 66 espécies (54,10\%) em comum entre as avaliações de 1984 e 2010. A maior proporção de aumento no número de espécies ocorreu para a categoria relativa às espécies nativas do Brasil. 
Tabela 2. Origem das espécies amostradas nos inventários de 1984 e 2010

Table 2. Origin of species sampled in the inventories of 1984 and 2010

\begin{tabular}{lcccccc} 
Origem & \multicolumn{2}{c}{$\mathbf{1 9 8 4}$} & \multicolumn{2}{c}{$\mathbf{2 0 1 0}$} & Espécies & $\begin{array}{c}\text { Proporção de } \\
\text { aumento (\%) }\end{array}$ \\
\cline { 2 - 5 } Exóticas no Brasil & Total & $\mathbf{P ( \% )}$ & Total & $\mathbf{P ( \% )}$ & comuns & aument, \\
Nativas de Curitiba & 48 & 51,06 & 66 & 54,10 & 33 & 37,50 \\
Nativas do Brasil & 23 & 24,47 & 31 & 25,41 & 19 & 34,78 \\
Não determinadas & 16 & 17,02 & 25 & 20,49 & 14 & 56,25 \\
\hline
\end{tabular}

Levando-se em conta as afirmações de Biondi e Leal (2008) de que espécies exóticas são aquelas espécies movidas de um ecossistema para outro, mesmo dentro de um país, a proporção para o total de espécies exóticas presentes em 2010 se torna igual a 74,59\% (91 espécies). Então, para o caso das espécies presentes apenas em 2010, a proporção de espécies exóticas se torna igual a 78,57\% (44 espécies). Portanto, constata-se que houve um aumento líquido de 47 espécies exóticas entre os anos de 1984 e 2010. Devido à baixa frequência de indivíduos arbóreos dessas espécies assume-se que as mesmas provêm de plantios feitos voluntariamente pela população.

Do total de 31 espécies nativas dos ecossistemas de Curitiba encontradas em 2010, apenas 12 delas (38,71\%) fazem parte de plantios regulares da prefeitura municipal. O restante compõe plantios voluntários ou regeneração natural presente nos canteiros.

Comparando-se os dados de 1984 e 2010, com relação às espécies nativas de Curitiba, constatou-se que 19 espécies são comuns a ambos os inventários e 12 espécies são exclusivas de 2010. Destas espécies exclusivas, apenas uma delas faz parte de plantios regularmente conduzidos pela prefeitura municipal, o que demonstra a falta de investimento na utilização de espécies florestais nativas da região. Porém, como já destacado, parte disso se deve à falta de pesquisas. Por outro lado, Biondi (2011) afirmou que em Curitiba a municipalidade demonstra preocupação com a introdução de espécies nativas do ecossistema local e com a erradicação de exemplares de espécies exóticas invasoras existentes na arborização de ruas e de áreas verdes.

Quanto às estimativas de diversidade obtidas com o índice de Shannon-Wiener (Tabela 3) constatou-se que em 1984 os valores variaram entre 0,49 para a parcela Rebouças 01 e 2,51 para a parcela Jardim Social, sendo que para o total amostrado foi obtido valor igual a 2,71. Para o ano de 2010, os valores foram maiores e variaram entre 1,16 para a parcela Rebouças 01 e 3,18 para a parcela Bacacheri 03, sendo que para o total amostrado foi obtido valor igual a 3,24. 
Tabela 3. Índice de diversidade de Shannon-Wiener para ambos os inventários

Table 3. Shannon-Wiener diversity index for both inventories

\begin{tabular}{|c|c|c|c|c|c|c|c|c|}
\hline \multirow{2}{*}{\multicolumn{2}{|c|}{ Parcela }} & \multicolumn{2}{|c|}{$\begin{array}{l}\text { Total de } \\
\text { indivíduos }\end{array}$} & \multicolumn{2}{|c|}{$\begin{array}{l}\text { Total de } \\
\text { espécies }\end{array}$} & \multicolumn{2}{|c|}{$\begin{array}{l}\text { Shannon- } \\
\text { Wiener }\end{array}$} & \multirow[t]{2}{*}{$p$-valor } \\
\hline & & 1984 & 2010 & 1984 & 2010 & 1984 & 2010 & \\
\hline 1 & Água Verde & 554 & 482 & 35 & 39 & 2,03 & 2,55 & $<0,01$ \\
\hline 2 & Alto da XV & 341 & 233 & 12 & 22 & 1,63 & 2,05 & $<0,01$ \\
\hline 3 & Bacacheri 01 & 295 & 298 & 22 & 24 & 1,01 & 1,72 & $<0,01$ \\
\hline 4 & Bacacheri 02 & 264 & 255 & 26 & 35 & 1,68 & 2,31 & $<0,01$ \\
\hline 5 & Bacacheri 03 & 110 & 369 & 11 & 57 & 1,55 & 3,18 & $<0,01$ \\
\hline 6 & Bigorrilho & 381 & 347 & 23 & 37 & 1,61 & 2,38 & $<0,01$ \\
\hline 7 & Boqueirão & 28 & 258 & 3 & 30 & 0,71 & 2,50 & $<0,01$ \\
\hline 8 & Centro & 122 & 78 & 7 & 13 & 0,86 & 2,18 & $<0,01$ \\
\hline 9 & Cristo Rei & 288 & 334 & 24 & 41 & 2,15 & 2,67 & $<0,01$ \\
\hline 10 & Jardim Social & 533 & 508 & 44 & 54 & 2,51 & 2,71 & 0,038 \\
\hline 11 & Mercês & 346 & 298 & 26 & 33 & 1,75 & 2,04 & 0,023 \\
\hline 12 & Portão & 277 & 200 & 14 & 23 & 1,54 & 2,02 & $<0,01$ \\
\hline 13 & Rebouças 01 & 111 & 100 & 5 & 9 & 0,49 & 1,16 & $<0,01$ \\
\hline 14 & Rebouças 02 & 398 & 350 & 19 & 29 & 1,39 & 1,96 & $<0,01$ \\
\hline 15 & Seminário & 300 & 250 & 44 & 24 & 2,04 & 2,11 & 0,622 \\
\hline & Total & 4348 & 4360 & 94 & 122 & 2,71 & 3,24 & $3,062 E-68$ \\
\hline
\end{tabular}

As diferenças observadas indicam que houve aumento no valor do índice de diversidade para todas as parcelas no período avaliado, porém de forma mais evidente para as parcelas 5,7 e 8 . Isso pode ser representado por espécies plantadas voluntariamente pela população, mas também pela melhor distribuição do quantitativo arbóreo entre as espécies durante a implantação ou manejo da arborização das ruas.

Os valores obtidos para o total de cada ano de avaliação divergem pouco daqueles obtidos em outros trabalhos realizados com a arborização de ruas, porém quando considerados os valores de cada parcela as divergências se acentuam. Silva Filho e Bortoleto (2005) encontraram valores entre 3,01 e 3,86 para os setores definidos após censo da arborização de ruas da cidade de Águas de São Pedro-SP. Meneghetti (2003) encontrou valores entre 1,96 e 2,61 para os estratos definidos para a cidade de Santos e de 2,63 para o total amostrado. Estas variações nos valores obtidos refletem as características da gestão da arborização de ruas das cidades, seja pelas diferenças na quantidade de espécies e de indivíduos arbóreos plantados, seja da metodologia adotada para a coleta de dados, incluindo espécies arbustivas, além das arbóreas, seja devido ao processo e método de inventário executado, principalmente com áreas amostrais diferentes.

Entretanto, a análise comparativa direta deve ser feita com cautela, pois de acordo com Magurran (2011), quando se compara os valores de diversidade de locais distintos deve-se cuidar com a rarefação dos dados a fim de ponderar as diferenças decorrentes de intensidades e de áreas amostrais diferentes, desde que a técnica de amostragem seja a mesma. Da mesma forma, também se deve observar se a base logarítmica adotada para o cálculo do índice de Shannon-Wiener, se $\log _{10}$ ou In, é a mesma entre as situações em 
comparação. Portanto, a partir dos estudos em comparação não se pode afirmar se a diversidade observada no inventário de Curitiba é melhor ou pior que aquela das outras cidades consideradas.

A análise comparativa dos valores pelo Teste de Hutcheson (MAGURRAN, 2011) revelou que houve diferença significativa $(p<0,01)$ para 12 parcelas, das 15 analisadas, e da mesma forma para a comparação entre os valores totais dos anos de 1984 e 2010.

Os resultados apresentados na Tabela 4 evidenciam que, para a análise comparativa entre os dados de 1984 e de 2010, as diferenças entre os valores do índice de Shannon-Wiener foram estatisticamente significativas $(p<0,01)$ para as três situações de comparação: composição total de espécies $(\mathrm{N}+\mathrm{E}+\mathrm{l})$, composição de espécies sem a inclusão das exóticas invasoras $(\mathrm{N}+\mathrm{E})$ e composição de espécies apenas considerando as nativas $(\mathrm{N})$.

Tabela 4. Comparação dos valores do índice de Shannon-Wiener entre os anos de 1984 e 2010, para o total amostrado $(\mathrm{N}+\mathrm{E}+\mathrm{I})$, para o total exceto espécies exóticas invasoras $(\mathrm{N}+\mathrm{E})$ e somente para as espécies nativas $(\mathrm{N})$

Table 4. Comparison of Shannon-Wiener index values between 1984 and 2010 for total data sampled $(\mathrm{N}+\mathrm{E}+\mathrm{l})$, for total data sampled except invasive alien species $(\mathrm{N}+\mathrm{E})$ and only for indigenous species $(\mathrm{N})$

\begin{tabular}{ccccccccc}
\multirow{2}{*}{ Comparação } & \multicolumn{2}{c}{$\begin{array}{c}\text { Total de } \\
\text { indivíduos }\end{array}$} & \multicolumn{2}{c}{$\begin{array}{c}\text { Total de } \\
\text { espécies }\end{array}$} & \multicolumn{2}{c}{ Shannon-Wiener } & \multirow{2}{*}{ p-valor } \\
\cline { 2 - 7 } & 1984 & 2010 & 1984 & 2010 & 1984 & 2010 & \\
N+E+l & 4348 & 4360 & 94 & 122 & 2,71 & 3,24 & $<0,01$ \\
N+E & 3566 & 3676 & 84 & 112 & 2,59 & 3,16 & $<0,01$ \\
N & 1009 & 1322 & 23 & 28 & 1,66 & 2,02 & $<0,01$ \\
\hline
\end{tabular}

Com o planejamento da eliminação das espécies exóticas das análises (tanto invasoras quanto não invasoras), no intuito de simular a remoção destas espécies das unidades amostrais avaliadas (Tabela 5), observou-se redução no valor do índice de diversidade (38,74\% para 1984 e $37,65 \%$ para 2010$)$, sendo que estas diferenças foram determinadas como significativas $(p<0,01)$ em ambos os anos de avaliação. Por outro lado, o planejamento da eliminação somente das espécies exóticas invasoras reduziu os valores do índice de diversidade de forma menos acentuada (4,43\% para 1984 e 2,47\% para 2010), porque a sua contribuição é pequena em relação à expressividade da diversidade observada. Para a realidade atual mensurada, correspondente ao ano de 2010, não foi constatada diferença significativa $(p>0,01)$ entre os valores do índice de Shannon-Wiener para a simulação de remoção das espécies exóticas invasoras consideradas. 
Tabela 5. Comparação dos valores do índice de Shannon-Wiener para o total amostrado (1) em 1984 e 2010, para o total exceto espécies exóticas invasoras (2) e somente para as espécies nativas (3)

Table 5. Comparison of Shannon-Wiener index values for total data sampled (1) in 1984 and 2010, for total data sampled except invasive alien species (2) and only for indigenous species (3)

\begin{tabular}{|c|c|c|c|c|c|c|c|}
\hline \multicolumn{8}{|c|}{ DADOS DE 1984} \\
\hline COMPARAÇÃO & \multicolumn{2}{|c|}{$\begin{array}{l}\text { Total de } \\
\text { indivíduos }\end{array}$} & \multicolumn{2}{|c|}{$\begin{array}{l}\text { Total de } \\
\text { espécies }\end{array}$} & \multicolumn{2}{|c|}{$\begin{array}{l}\text { Shannon- } \\
\text { Wiener }\end{array}$} & $p$-valor \\
\hline 1---2 & 4348 & 3566 & 94 & 85 & 2,71 & 2,59 & $<0,01$ \\
\hline 1---3 & 4348 & 1009 & 94 & 23 & 2,71 & 1,66 & $<0,01$ \\
\hline 2---3 & 3566 & 1009 & 85 & 23 & 2,59 & 1,66 & $<0,01$ \\
\hline \multicolumn{8}{|c|}{ DADOS DE 2010} \\
\hline COMPARAÇÃO & \multicolumn{2}{|c|}{$\begin{array}{c}\text { Total de } \\
\text { indivíduos }\end{array}$} & \multicolumn{2}{|c|}{$\begin{array}{l}\text { Total de } \\
\text { espécies }\end{array}$} & \multicolumn{2}{|c|}{$\begin{array}{c}\text { Shannon- } \\
\text { Wiener }\end{array}$} & $p$-valor \\
\hline $1--2$ & 4360 & 3676 & 122 & 113 & 3,24 & 3,16 & 0,011 \\
\hline 1---3 & 4360 & 1322 & 122 & 28 & 3,24 & 2,02 & $<0,01$ \\
\hline 2---3 & 3676 & 1322 & 113 & 28 & 3,16 & 2,02 & $<0,01$ \\
\hline
\end{tabular}

O resultado comparativo entre as situações 1 e 2 de simulação (Tabela 5), sem significância estatística para o ano de 2010, demonstra que as espécies exóticas invasoras, na atual composição da arborização de ruas, não contribuem com a expressividade do valor do índice de Shannon-Wiener, o que poderia mascará-lo. Neste sentido, Isernhagen, Le Bourlegat e Cardoni (2009) chamam a atenção para os resultados dos índices de diversidade, pois a divulgação de altos valores de índices de diversidade na arborização pode não indicar uma boa qualidade desta porque pode haver o mascaramento da presença de espécies exóticas e principalmente das exóticas invasoras.

Por conta disso, a remoção desta classe de espécies da composição da arborização de ruas não afetaria a expressividade do índice se o mesmo fosse utilizado como indicador de qualidade da gestão da arborização e de sua sustentabilidade. Isto leva a crer que a eliminação das mesmas, nas parcelas amostradas, poderia ser feita sem qualquer preocupação. Porém, toda e qualquer prática de remoção e substituição de árvores na arborização de ruas deve ser feita de forma planejada e programada, evitando-se a eliminação massiva e em uma única etapa a fim de evitar impactos visuais repentinos e a eliminação de grande massa verde que contribui com a menor amplitude térmica das ruas. 


\section{CONCLUSÕES}

A diversidade de espécies na arborização de ruas de Curitiba aumentou de 1984 a 2010 nas unidades amostrais, mas a diferença foi significativa apenas para 12 parcelas, das 15 avaliadas, bem como, entre os valores totais.

Houve redução na proporção das espécies exóticas invasoras mais freqüentes (Ligustrum lucidum e Melia azedarach), porém houve aumento na proporção de outras espécies com caráter invasor como Eriobotrya japonica, Hovenia dulcis e Pittosporum undulatum.

A remoção de indivíduos de espécies exóticas invasoras das análises não alterou significativamente o valor do índice de Shannon-Wiener para o ano de 2010, porém a remoção conjunta com indivíduos das espécies exóticas alterou significativamente o valor do índice.

Este índice, apesar de mascarar a presença de espécies exóticas invasoras, pode ser utilizado como ferramenta auxiliar ao planejamento e gestão da diversidade de espécies na composição da arborização de ruas.

\section{REFERÊNCIAS}

BIONDI, D.; LEAL, L.; COBALCHINI, J. L. Tratamentos silviculturais em mudas de Allophylus edulis (A. St.-Hil., Cambess. \& A. Juss.) Radlk. para arborização de ruas. Floresta, Curitiba, v.37, n.3, p. 437 - 444, 2007.

BIONDI, D.; LEAL, L. Caracterização das plantas produzidas no Horto Municipal da Barreirinha, Curitiba/PR. Revista da Sociedade Brasileira de Arborização Urbana, Piracicaba, v.3, n.2, p. 20-36, 2008.

BIONDI, D.; PEDROSA-MACEDO, J. H. Plantas invasoras encontradas na área urbana de Curitiba (PR). Floresta, Curitiba, v.38, n.1, p. 129 - 144, 2008.

BIONDI, D. Introdução de espécies na arborização de ruas. In: BIONDI, D.; LIMA NETO, E. M. Pesquisas em arborização de ruas. Curitiba: O Autor, 2011, p. 9-28.

BLUM, C. T.; BORGO, M.; SAMPAIO, A. C. F. Espécies exóticas invasoras na arborização de vias públicas de Maringá - PR. Revista da Sociedade Brasileira de Arborização Urbana, Piracicaba, v.3, n.2, p. 78-97, 2008.

BOBROWSKI, R. Estrutura e dinâmica da arborização de ruas de Curitiba, Paraná, no período 1984 - 2010. 144f. Dissertação (Mestrado em Engenharia Florestal) - Setor de Ciências Agrárias, Universidade Federal do Paraná, Curitiba, 2011. 
BOBROWSKI, R.; BIONDI, D. Caracterização do padrão de plantio adotado na arborização de ruas de Curitiba, Paraná. Revista da Sociedade Brasileira de Arborização Urbana, Piracicaba, v.7, n.3, p.20-30, 2012.

CALIXTO JUNIOR; J. T.; SANTANA FILHO; G. M.; LIRA FILHO, J. A. Analise quantitativa da arborização de Lavras da Mangabeira, CE, nordeste do Brasil. Revista da Sociedade Brasileira de Arborização Urbana, Piracicaba, v.4, n.3, p.99-109, 2009.

EMER, C.; FONSECA, C. R. Araucaria forest conservation: mechanisms providing resistance to invasion by exotic timber trees. Biological Invasions, Amsterdan, v.13, n.1, p. 189-202, 2010.

FALLEIROS, R. M.; ZENNI, R. D.; ZILLER, S. R. Invasão e manejo de Pinus taeda em campos de altitude do Parque Estadual do Pico do Paraná, Paraná, Brasil. Floresta, Curitiba, v.41, n.1, p. 123-134, 2011.

GALVIN, M. F. A methodology for assessing and managing biodiversity in street tree populations: a case study. Journal of Arboriculture, Champaign, IL, v.25, n.3, p.124-128, 1999.

INSERNHAGEN, I.; LE BOURLEGAT, J. M. G.; CARBONI, M. Trazendo a riqueza arbórea regional para dentro das cidades: possibilidades, limitações e benefícios. Revista da Sociedade Brasileira de Arborização Urbana, Piracicaba, v.4, n.2, p.117-138, 2009.

KENNEY, W. A.; VAN WASSENAER, P. J. E.; SATEL, A. L. Criteria and indicators for strategic urban forest planning and management. Arboriculture \& Urban Forestry, Champaign, v. 17, n. 3, p. 108-117, 2011.

MAGURRAN, A. E. Medindo a diversidade biológica. Curitiba: Editora da UFPR, 2011.

MENEGHETTI, G. I. P. Estudo de dois métodos de amostragem para inventários da arborização de ruas dos bairros da orla marítima do município de Santos-SP. $100 f$. Dissertação (Mestrado em Recursos Florestais) - Escola Superior de Agricultura "Luiz de Queiroz", Universidade de São Paulo, Piracicaba, 2003.

MOONEY, H. A. Invasive alien species: the nature of the problem. In: MOONEY, $\mathrm{H}$. A.;MACK, R. N.;MCNEELY, J. A.;NEVILLE, L. E.;SCHEI, P. J.;WAAGE, J. K. Invasive Alien Species: a new synthesis. Washington, DC: Island Press, 2005, p. 1-15.

MORO, M. F.; WESTERKAMP, C. The alien street trees of Fortaleza (NE Brazil): qualitative observations and the inventory of two districts. Ciência Florestal, Santa Maria, v.21, n.4, p. 789-798, 2011.

PIRES, N. A. M. T.; MELO, M. S.; OLIVEIRA, D. A.; XAVIER-SANTOS, S. A arborização urbana do município de Goiandira/GO - caracterização quali-quantitativa e proposta de manejo. Revista da Sociedade Brasileira de Arborização Urbana, Piracicaba, v.5, n.3, p.185-205, 2010.

RAUPP, M. J.; CUMMING, A. B.; RAUPP, E. C. Street tree diversity in eastern North America and its potential for tree loss to exotic borers. Arboriculture \& Urban Forestry, Champaign, v. 32, n. 6 , p. 297-304, 2006. 
ROSA, S. F.; LONGHI, S. J.; LUDWIG, M. P. Aspectos florísticos e fitossociológicos da reserva Capão de Tupanciretã, Tupanciretã, RS, Brasil. Ciência Florestal, Santa Maria, v.18, n.1, p. 15-25, 2008.

SILVA FILHO, D. F.; BORTOLETO, S. Uso de indicadores de diversidade na definição de plano de manejo da arborização viária de Águas de São Pedro-SP. Árvore, Viçosa, v.29, n.6, p.973-982, 2005.

SILVA, P. H. M.; POGGIANI, F.; MORI, E. S.; DIAS, C. T. S.; CIERO, L. Potencial de invasão de eucalipto pelas sementes produzidas nos plantios comerciais. Circular Técnica IPEF, n. 203, p. 1-7, 2011.

SREETHERAN, M.; ADNAN, M.; KHAIRIL AZUAR, A. K. Street tree inventory and tree risk assessment of selected major roads in Kuala Lumpur, Malaysia. Arboriculture \& Urban Forestry, Champaign, v. 37, n. 5, p. 226-235, 2011.

STRANGHETI, V.; SILVA, Z. A. V. Diagnóstico da arborização das vias públicas do município de Uchoa-SP. Revista da Sociedade Brasileira de Arborização Urbana, Piracicaba, v.5, n.2, p.124-138, 2010.

TEIXEIRA, I. F.; SILVA, R. M.; TATSCH, G. L. Compatibilidade da arborização de ruas da Avenida Celestino Cavalheiro, São Gabriel-RS. Floresta e Ambiente, v. 18, n. 4, p.438-450, 2011. 